\title{
REFUNCIONALIZAÇÃO DA ESFERA PÚBLICA E OS PROCESSOS COMUNICACIONAIS*
}

\author{
Anelisa MARADEI ${ }^{* *}$
}

\section{RESUMO:}

Neste artigo, discorreremos sobre as novas configurações da comunicação na esfera pública durante a contemporaneidade. Em nosso entendimento, devem-se retomar as discussões sobre a esfera pública, sob a perspectiva dos impactos ocasionados pelas tecnologias da informação e da comunicação (TICs), que modificaram as condições espaço-temporais e a forma como os cidadãos passaram a relacionar-se com as instituições, os governos, os partidos políticos e entre si. Para desenvolver essas articulações, utilizamos a revisão bibliográfica, partindo do conceito de esfera pública adotado por Habermas em Mudança Estrutural da Esfera Pública [1962] (2014), revisto em sua obra Direito e Democracia (1997). Também buscamos auxílio a nossas sustentações em autores que trabalham com estes conceitos: ativismo, esfera pública digital e ciberdemocracia.

Palavras-chave: Comunicação; Esfera Pública; Democracia; Opinião Pública.

\section{INTRODUCÃO:}

A Revolução Informacional (CASTELLS, 1999, 2003, 2005) constitui processo que vem avançando. Em meados de 1990, a Internet acelerou esse cenário, impactando as formas de comunicação cotidianas. A partir da internet e do uso, em larga escala, das redes sociais digitais, estabeleceu-se a

\footnotetext{
* Trabalho apresentado no GT 5 - Comunicação e Política, do PENSACOM BRASIL, 2016.

** Mestre e Doutoranda em Comunicação Social pela Universidade Metodista de São Paulo, Professora dos Cursos de Pós-Graduação em Comunicação Lato Sensu da Universidade Metodista de São Paulo e da Universidade Municipal de São Caetano do Sul.
} 
comunicação interativa. Essa nova forma permite "[...] a interação social ativa e em mão dupla entre os seres humanos, ao ensejar o aparecimento de redes sociotécnicas participativas que transcendem a sua pura e simples interligação social, como ocorria na esfera da velha mídia” (RÜDGER, 2011, p.13).

Neste artigo, discorreremos sobre as novas configurações da comunicação na esfera pública durante a contemporaneidade. Nessa direção, partimos do princípio de que, nas democracias atuais, temos a oportunidade e o desafio de encarar, de outra forma, muitos dos problemas que já enfrentávamos no passado. Há novas possibilidades para o enfrentamento cotidiano de questões importantes, como o abuso de poder, a censura, a corrupção, o desvio de verbas públicas etc. Para tanto, iniciamos nossas ponderações com uma breve explanação sobre o conceito de esfera pública, como proposto por Habermas em sua obra Mudança Estrutural da Esfera Pública (2014).

A escolha da obra como marco teórico deve-se ao fato de o autor ter incorporado, em suas discussões, aspectos relevantes para o campo da comunicação, como o surgimento da imprensa e suas transformações posteriores, ao implementar-se como atividade comercial nos séculos XIX e XX. O fato é que chegamos ao século XXI, oportunidade em que se aceleram os processos das redes sociais digitais, com profundas alterações no campo da esfera pública.

Nesse sentido, importa ressaltar que não mais se encontra uma esfera pública como a inicialmente proposta por Habermas (2014) na obra citada, de 1962. Ele entendia, por esfera pública, a reunião de um público, formado por pessoas privadas, que construíam uma opinião com base na racionalidade do melhor argumento. O primeiro requisito da esfera pública seria a palavra, a comunicação. Depois, vinham os interesses, as vontades e as pretensões dos cidadãos.

Atualmente, todavia, devem-se retomar as discussões sobre a esfera pública sob a perspectiva dos impactos nela ocasionados pelas tecnologias da informação e da comunicação (TICs), que modificaram as condições espaço-temporais e a forma como os cidadãos se relacionam com as instituições, os governos e os partidos políticos. A par da questão tecnológica, nota-se seu forte impacto sobre a forma como os atores sociais atuam e exercem seu papel nas democracias. As implicações decorrentes de todas essas novas ambientações serão detalhadas a seguir.

\section{MUDANÇAS NA ESFERA PÚBLICA}

Há diversas definições para o conceito de esfera pública. De acordo com Habermas (Habermas, 2014, p.21), "a esfera pública [...] busca a racionalização do poder político, procurando estabelecer novas bases de legitimação para 
sua origem e seu exercício: o consentimento racional entre pessoas autônomas, livres e iguais". Para Hannah Arendt (1959, p.52), a esfera pública é o "mundo comum" que "nos reúne e, assim, evita que caiamos uns sobre os outros". Para Fuchs (2015, p.12), a esfera pública/ sociedade civil ${ }^{1}$ seria um espaço que "conectaria a cultura, a economia e a política e, assim, criaria sobreposições entre a esfera pública e estes âmbitos: o a esfera sociopolítica, a esfera socioeconômica e a esfera sociocultural". Como se a sociedade pudesse ser entendida pela composição de esferas diferentes e conectadas: a economia é a esfera da produção do valor de uso; a política, o espaço onde as decisões coletivas são tomadas e a cultura, a que cria os significados sociais e os valores morais (FUCHS, 2008).

Habermas apresenta, na construção de sua obra, dois momentos quanto ao conceito de esfera pública. Um mais pessimista, até os anos 1990, em que, como proposto por Avritzer (2014, p.75), "ele acha que os meios eletrônicos são uma forma de dominação", ainda com forte influência da Teoria Crítica. Já no segundo, sua argumentação amplia-se em direção à capacidade do sistema político em absorver as formas de tecnologia. É o que se nota em Direito e Democracia (HABERMAS, 1997).

Entre 1989 e 1992, Habermas foi, pela primeira vez, desde os anos 1960, compelido a considerar e a rever sua posição sobre a esfera pública. Em decorrência disso, Mudança Estrutural da Esfera Pública ganha a sua primeira tradução americana em 1989, celebrada com um famoso congresso sobre a esfera pública, no qual Habermas foi confrontado com releituras da sua obra e reexames do conceito por ele desenvolvido em 1962 (GOMES, 2008, p.69). O resultado desse congresso constituiu uma influente coletânea, organizada por Craig Calhoun: Habermas and the Public Sphere, publicada em 1992. No mesmo ano, o autor lançou Direito e Democracia, obra "em que a noção de esfera pública é, pela primeira vez em trinta anos, readmitida ao patrimônio argumentativo do pensador alemão" (GOMES, 2008, p.70).

De consagrado nos anos 1960 a questionado nos 1980, o conceito de Habermas, por ele atualizado em Direito e Democracia, "expressa e, ao mesmo tempo, leva, ao ponto mais alto, um processo de consagração da ideia de esfera pública como palavra-chave importante em teoria social" (2008, p.70). Essa ideia converte-se na de "deliberação pública" e passa a representar o ponto de partida de toda a corrente contemporânea da teoria sobre a democracia deliberativa.

1 O autor utiliza esfera pública e sociedade civil como sinônimos cidadãos livres e iguais, excluídos mulheres e negros, por exemplo. 
Pensando em Habermas, podemos dizer que o mérito do autor, ainda quando articulou seu pensamento na obra clássica Mudança Estrutural da Esfera Pública [1962] (2014), foi traçar um ponto de partida ao retratar a reconstrução histórica de diferentes tipos de esfera pública. Começou com a distinção entre o público e o privado na Grécia clássica. Depois, passou pelo gradativo esgarçamento dessa diferenciação na Idade Média e pela emergência de esfera pública representativa nas cortes e nos palácios. Por fim, culminou nas novas configurações e mediações entre o privado e o público, numa esfera pública burguesa liberal da sociedade moderna, e nas transformações posteriores nas democracias de massa do Estado de bem-estar social, com toda sua complexidade ainda a desvendar (HABERMAS, 2014).

Seguindo a contribuição do autor, nas cidades-estado da Grécia clássica, os habitantes reuniam-se em lugares comuns para debater questões, fazer propostas e tomar decisões. O "exercício do poder político era relativamente visível: as intervenções e argumentações dos participantes podiam ser vistas e ouvidas por aqueles ali reunidos, e todos tinham direitos iguais de manifestar a própria opinião e de ser ouvidos", como nos recorda Thompson (2014, p.165). Entretanto tratava-se de uma esfera pública de acesso restrito, pois só podiam participar homens atenienses, com idade superior a 20 anos. Mulheres, escravos e "metecos" (estrangeiros) eram excluídos.

Já na esfera pública burguesa, diferentemente do que se observava na Grécia clássica, a liberdade não constituía atributo exclusivo da vida pública, apesar de seguir o princípio do uso público da razão por

A sociedade moderna viu o crescimento da economia capitalista e, no Estado moderno, estabeleceram-se esferas relativamente autônomas e interconectadas, pois a economia não mais fazia parte dos lares privados. $\mathrm{Na}$ verdade, havia, por volta do século XVIII, na Europa, um ambiente propício a novos locais de socialização, presentes nos principais centros urbanos da Europa, incluindo salões e cafés, que se tornavam lugares de discussão. Como afirma Thompson (2014), eram "lugares de discussão e ambientes sociais onde as elites instruídas podiam interagir entre si e com a nobreza em posição mais ou menos de igualdade".

Para Habermas (2014, p.135), a "esfera pública burguesa pode ser entendida, antes de mais nada, como a esfera de pessoas privadas que se reúnem em um público". As pessoas supervisionavam, procuravam influenciar e, de alguma maneira, controlar o poder, mas elas mesmas não possuíam uma parte do poder do Estado, como acontecia com a nobreza. Buscavam, em fóruns informais (café, salões) atacar a dominação vigente e manter sua liberdade econômica. Nesse contexto, o desenvolvimento do capitalismo mercantil, junto com as transformações institucionais do poder político (séculos XVII e XVIII), 
criaram as condições para a emergência de um novo tipo de esfera pública nas origens da Europa moderna. Sobre a questão, Avritzer e Costa ponderam:

A burguesia é a primeira classe governante cuja fonte de poder é independente do controle do Estado e que se localiza no nível privado. Sua relação com o poder é, nesse sentido, estruturalmente diferente de outras classes na história, uma vez que renuncia ao exercício direto do governo, reivindicando, contudo, o direito de ter conhecimento do que faz o Estado. (AVRITZER e COSTA, 2004, p. 707)

Somado a todo esse contexto, no processo de mudança estrutural da esfera pública, Habermas (2014) atribuiu particular importância ao surgimento da imprensa. De fato, a esfera pública burguesa utilizaria a imprensa de opinião, em primeiro lugar, para mediar o uso público de suas razões, servindo de veículo para expressar os pontos de vista de modo aberto; segundo, para fazer essas opiniões circularem em vários ambientes (MAIA, 2009). Num primeiro momento, organizou-se o comércio de jornais sob a forma de pequenos empreendimentos artesanais.

Inicialmente, o cenário era de imprensa de notícias, paulatinamente transformada em imprensa de convicções, na qual "a redação de avisos passou a concorrer com o jornalismo de escritores" (2014, p.395). A princípio, esses eruditos passaram a sustentar, sozinhos, o risco econômico dos jornais, pois forneciam material, pagavam colaboradores etc.

Para Thompson (2010, p.16), "enquanto a emergência da economia capitalista implicava o crescimento da troca de bens, as sociedades do início do período moderno na Europa também testemunhavam, a partir dos séculos XVI e XVII, uma crescente troca no nível da informação, precipitada pela ascensão do jornal impresso e de outros periódicos". É o que Habermas (2014) descreve como a emergente esfera pública da sociedade civil, ou a "esfera pública burguesa". Esse espaço funcionaria como mediador entre o domínio público do Estado, por um lado, e o privado do domić́lio e da família, por outro.

Entretanto, com as mudanças a ocorrer no perfil da imprensa, houve "a refuncionalização do princípio da esfera pública", que se baseou em sua reestruturação enquanto esfera ligada à mudança de sua instituição mais proeminente. À medida que a imprensa passou a assumir características comerciais, "a esfera pública deixa de ser exclusivamente uma parte do domínio privado" (HABERMAS, 2014, p.395). Dessa forma, percebe-se que a extin- 
ção da esfera pública burguesa se deveu ao desaparecimento das instituições que tinham proporcionado um fórum para que ela se estabelecesse, como a imprensa periódica, que se tornou parte de um mundo de instituições com interesses comerciais. No tocante ao papel da imprensa na modificação da esfera pública burguesa, Thompson afirmou que:

A comercialização da mídia altera o seu caráter profundamente: o que antes era um fórum exemplar de debate crítico-racional torna-se apenas mais um domínio de consumo cultural, e a esfera pública burguesa esvazia-se num mundo fictício de imagens e opiniões. (THOMPSON, 2014, p.109).

Paralelamente, com o tempo, o Estado adquiriu maiores responsabilidades na administração do bem comum aos cidadãos, enquanto os grupos de interesse organizados se tornaram mais reivindicantes e participativos no processo político. E se hoje, como nos recorda Thompson (2014), comumente associamos poder à política, isto é, às ações de indivíduos agindo em nome do Estado, é porque estes se tornaram, particularmente, centros importantes de concentração de poder no mundo.

\section{ESFERA PÚBLICA EM DIREITO E DEMOCRACIA}

A esfera pública burguesa floresceu em condições propícias no século XVIII e entrou em decadência, ou reconfigurou-se, nos séculos XIX e XX. Em função dessas alterações históricas, em Direito e Democracia, Habermas (1997) retoma a discussão do conceito de esfera pública sob nova perspectiva. O cerne do argumento do autor repousa, agora, na preocupação em resolver o problema de conceder, ou reconhecer, uma função relevante ao processo e ao resultado da formação da opinião e da vontade em sociedades democráticas. Para Gomes (2008, p.81), “o problema consiste, portanto, em decidir qual o lugar e o alcance da opinião e da vontade dos cidadãos no modo como, na democracia, são produzidas as decisões políticas".

$\mathrm{Na}$ perspectiva de Habermas, apresentada nessa nova fase, a ligação entre os cidadãos, suas opiniões e vontades e o sistema que, efetivamente, produz decisões obrigatórias para todos os membros da sociedade, deve partir de um modelo de democracia que evite, ao mesmo tempo, as dificuldades do modelo liberal e as do republicano. Sobre a questão, Gomes (2008) afirma que, neste, deve haver processos coletivos, por meio dos quais se formem a opinião pública e a vontade geral, ações que demandam interações discursivas e consenso para a formação de leis, as políticas públicas etc. O que os republicanos advogam é que o poder comunicativo se sobreponha ao administrativo.

$\mathrm{Na}$ contrapartida, a perspectiva liberal caminha noutro sentido, já que 
adota diferentes pressupostos. De fato, porque a política se caracteriza, essencialmente, como luta por posições na busca do poder administrativo, o processo para formar a opinião e a vontade, em qualquer dos meios da sua realização, constitui, basicamente, uma competição entre grupos a moverse estrategicamente. A meta deles é assegurar, ou adquirir, posições, numa competição cujo êxito, ou fracasso, se mede pela aprovação dos cidadãos, quantificada como votos.

A compatibilidade entre um modelo e outro constitui a temática que se vai apresentar em, praticamente, toda a obra Direito e Democracia. Nela, Habermas insiste que um teste da legitimidade do processo democrático consiste em verificar em que medida as deliberações institucionalizadas, que constituem o modo de produção de decisões, se encontram abertas aos aportes e às pressões da opinião pública, ou seja, abertas à circulação informal da comunicação política. Como sugere Habermas, a estrutura fundamental, nesta segunda fase de sua obra, seria:

A compatibilidade entre, de um lado, os exigentes requisitos da comunicação pública política na formação da opinião e da vontade coletivas, de matriz republicana, e, do outro, o fato de que a opinião pública não é um sistema socialmente institucionalizado para produzir leis nem políticas, [...\} próprias de um modelo discursivo de democracia [...] é uma das peças fundamentais da estrutura conceitual da proposta habermasiana (HABERMAS, 2008, p.77)

De acordo com o autor, o problema consiste em decidir quais o lugar e o alcance da opinião e da vontade dos cidadãos sobre o modo como, na democracia, se produzem as decisões políticas. Dessa forma, nossas articulações se basearão na perspectiva proposta por Habermas no tocante à expressão "esfera pública", considerando-a uma das junções no processo de a sociedade produzir uma vontade comum e uma opinião compartilhada.

Para efeito de coerência argumentativa, a partir de agora, designaremos "a esfera pública como um meio de formação da opinião e da vontade públicas" e "entenderemos a comunicação, a discussão e a deliberação públicas como o modo pelo qual tal formação se realiza na esfera pública” (Maia, 2008, p.75). A mídia, nesse processo, desempenha, sem dúvida, um papel central, como disseminadora de informações aos cidadãos.

Para dar resposta a questões fundamentais sobre as demandas, levantadas pelos cidadãos no processo democrático, não podemos negligenciar a centralidade, cada vez maior, da comunicação mediada nos processos cotidianos, inclusive sobre os políticos. Paralelamente, como pondera Maia (2008, p.166), "as associações voluntárias são vistas como agentes que contribuem 
para articular interesses coletivos, proporcionar voz, sustentar deliberações, a fim de contribuir nos processos de definição de agendas políticas [....]". Por fim, cabe registrar que, por deliberações, tanto a autora, quanto nós entendemos que as decisões não são específicas para determinado momento, mas funcionam como o "processo argumentativo" feito em público.

\section{OPINIÃO PÚBLICA}

No tocante à importância da mídia no contexto e na composição da esfera pública, Habermas (2014), apesar de reconhecer a presença da imprensa quando escreveu Mudança Estrutural da Esfera Pública, continuava a definir a esfera pública como um processo centrado no diálogo face a face. Ele acreditava que, a partir do momento em que a mídia entrou no cenário histórico, reduziu-se a qualidade desse diálogo. Em nosso entendimento, a questão central não constitui a presença da mídia, mas a ausência de pluralismo no debate, de interações e de informações qualificadas.

Walter Lippmann (2010) começou seu livro seminal Opinião Pública, primeira edição de 1922 , com a história sobre uma ilha remota em que viviam algumas pessoas de nacionalidades diferentes, sem conexão com o mundo exterior, a não ser um barco a vapor, que, a cada 60 dias, trazia, entre outros produtos, os jornais. Entre uma vinda e outra, eclodiria a guerra e a Alemanha entraria em disputas com a Grã-Bretanha e a França, colocando em conflito, de uma hora para a outra, as pessoas da ilha, até então, a viver como amigas, isoladas das notícias.

Lippman usa essa história para ilustrar o poder de os jornais moldarem, em nossa mente, a interpretação que fazemos do mundo social. Entretanto, se há força nas notícias veiculadas pelos meios de comunicação de massa, como os jornais, é importante observar, como bem pondera Lippmann (2010, p.304), que "a notícia e a verdade não são a mesma coisa, e precisam ser claramente distintas". Segundo o autor, a função da notícia consiste em sinalizar um evento, enquanto a da verdade, em trazer, à luz, os fatos escondidos, pô-los em relação um com o outro e produzir uma imagem da realidade com base na qual os homens possam atuar.

Dessa forma, não seria possível chegarmos à verdade numa sociedade pouco plural, onde não tivéssemos acesso a uma diversidade de informações que nos permitisse realizar contrapontos e formatar nosso próprio ponto de vista. Outro aspecto essencial consiste nas informações qualificadas e idôneas e que venham, não só da esfera midiática, mas da política e de outros contextos que nos ajudem na composição sustentável, não de meras informações, mas de conhecimento.

O conceito de opinião pública nasceu, segundo Di Felice (2010), quando 
da substituição da sociedade feudal, da decadência do modelo baseado no poder do rei, que impunha leis inquestionáveis, e do surgimento da burguesia. "A sociedade que nasce daí não é mais assentada em valores divinos, 'justos' e, sim, em códigos racionais, que têm mais a ver com a necessidade de organizar as coisas ao gosto da nova classe que ascende ao poder e vai fazer leis para defender seus interesses". (DI FELICE, 2010)

Entretanto, ao longo da história, o conceito de opinião pública foi contestado por uma série de teorias, principalmente depois do surgimento da mídia de massa e do uso que o nazismo e os regimes totalitários, em geral, fizeram dela. Isso tem levado alguns autores a contestar esse conceito, ponderando o papel manipulativo da opinião pública. Alguns chegam a dizer que não existiria a opinião pública.

$\mathrm{Na}$ discussão contemporânea das democracias abatidas por crises institucionais e de confiança, tem-se retomado o debate sobre o conceito de opinião pública. Isso vem ocorrendo pela necessidade de novos atores em inserir-se na esfera pública, motivados pelas oportunidades oriundas das tecnologias da informação e da comunicação para problematizar temas tradicionais da democracia, tais como representatividade, aperfeiçoamento das formas de participação dos cidadãos, estabelecimento de direitos, entre outros.

Entre os muitos conceitos clássicos que encontramos sobre opinião pública, há os que se encaminham sob a influência da Escola de Frankfurt ${ }^{2}$. Esse é o conceito adotado, por exemplo, por Lippmann (2010), para quem os mapas mentais que resultam da exposição dos indivíduos à mídia moderna jamais serão capazes de refletir a verdade. Trata-se de um conceito crítico. A opinião pública, na visão do autor, seria uma ilusão, na medida que não seria possível chegar a um conceito unificado.

Além disso, a tese proposta por Lippmann traz a questão de que convivemos com os estereótipos, que também funcionam como entraves à consolidação da opinião pública, pois formamos imagens do mundo exterior a partir de enquadramentos induzidos pelos antepassados e pela mídia $(2010,239)$. Somente poucas pessoas iriam além das fronteiras das descrições legadas o por pais e professores, buscando fontes alternativas, além dos meios tradicionais de comunicação. Sairiam, assim, de seu ambiente para conhecer outras perspectivas, ampliando seu campo de visão, os horizontes e as perspectivas.

Entretanto, hoje, não podemos negar haver possibilidades de cruzar fronteiras sem sair do lugar, de buscar informações variadas e questiona-

2 Além de Lippmann, são herdeiros dessa corrente crítica Adorno, Horkheimer e o filósofo alemão Jürgen Habermas (nascido em 1929). 
mentos por meio de um simples click, bastando, para isso, que tenhamos condições de selecionar essa informação, transformando-a em conhecimento.

Não menos crítica é a visão de Bordieu sobre a opinião pública. $\mathrm{O}$ autor, em sua obra Sobre o Estado (2014), sustenta que: “[....] a opinião pública é a opinião dos que são dignos de ter uma opinião. Há uma espécie de definição censitária da opinião pública, como opinião esclarecida, como opinião digna desse nome". (BOURDIEU, 2014 p.101). Ele também acredita que, para se estabelecer a vontade das maiorias, inclusive no campo das legislações e do direito em sociedades democráticas, quando se trata de terrenos não constituídos (aborto, pena de morte, questões políticas polêmicas, como o impeachment da presidente do Brasil), em que há um "vazio jurídico", sempre se encontra espaço para o jogo duplo, isto é, a opinião de todos e a opinião autorizada e eficiente, um subconjunto restrito da opinião pública democraticamente definida. Objetivamente, para ele, "a verdade dos dominantes torna-se a de todos". O autor estabelece a crítica a partir da constatação de que as pessoas mais bem informadas disporiam de instrumental superior, de maior preparo e de melhor capacidade de argumentação que a maioria, impondo seus pontos de vista e difundindo-os.

Devido à grande influência das tecnologias da informação e comunicação, o conceito de opinião pública também se vem rediscutindo. Para Lévy e Lemos (2010), a opinião pública forja-se a cada dia em listas de discussão, fóruns, blogs e demais dispositivos de comunicação, próprios às comunidades sociais. Para os autores, nesse ambiente, definem-se novas formas de expressão: pensamentos e opiniões são expressos por pessoas comuns, por atores sociais que as produzem, utilizando-se de ferramentais digitais e de dispositivos móveis. Esses cidadãos expressam suas próprias opiniões sem a intermediação de jornalistas. A internet amplia a circulação da palavra. Quem ganha com isso, segundo os adeptos dessa vertente, é o cidadão, na medida que cresce a liberdade de produção, de consumo e de distribuição das informações. "Amplia-se, dito de outro modo, a 'esfera pública' e, consequentemente, a esfera da ação comunicativa", como propõem Lévy e Lemos (2010, p. 89).

Mas, mais do que influenciar pessoas, é importante ponderar, quando se pensa em opinião pública atual, a centralidade da mídia na definição do que precisa, ou não, ser discutido pelos cidadãos no seu cotidiano e na esfera política. O que não passa pela mídia estaria, assim, fora da agenda política e social. Nessa perspectiva, a nova esfera pública constitui uma arena midiática, cujas opiniões devem ser observadas em toda a sua complexidade. 
A esfera pública constitui espaço "aberto a todos", na concepção de Habermas, embora possamos fazer muitas ressalvas a essa afirmativa. Segundo ele, a tarefa da esfera pública seria engajar as pessoas em um "debate público crítico" (Habermas, 1991, p.52). Para que isso ocorra de forma consistente, há de haver cidadãos em condições para tanto. Isso passa pela inclusão digital, pelo desenvolvimento da cultura política, pela regulamentação do setor de comunicação, pelo pluralismo midiático e pela ampliação da informação política qualificada.

Se Habermas já trazia a ideia de esfera pública como espaço aberto a todos, autores como Castells (2013, 2015), Di Felice (2012, 2014) e Lemos $(2010,2014)$ têm a expectativa de que as redes digitais permitam uma relação sem intermediários entre a esfera civil e a política, minimizando as influências da esfera econômica e das indústrias da informação de massa, que ainda exercem forte influência sobre os processos políticos. Fala-se, até na literatura acadêmica, em termos como ciberdemocracia (LEMOS e LÉVY, 2010) e democracia digital. Entretanto ainda ocorre ampla e pertinente discussão acerca das práticas e das possibilidades em torno da nova infraestrutura tecnológica eletrônica, proporcionada pelos computadores em rede e pelos dispositivos móveis.

Nem a primeira perspectiva, de espaço aberto a todos, nem a de uma relação entre os atores sociais sem intermediários pode, contudo, ser contemplada sem as devidas ponderações. Não podemos, por exemplo, fechar os olhos ao fato de que, para cada possibilidade aberta pela rede ao cidadão, há também a necessidade de se pensar na perspectiva do jogo do poder instituído na rede, especialmente no campo político.

Mas, ainda assim, a realidade é que as novas tecnologias, as redes sociais digitais, impactam a formação da opinião pública, o que é relevante a nossas observações. Para Felice, "a opinião pública muda de caráter de acordo com a tecnologia informativa de uma época" (DI FELICE, 2010). Dentro dessa perspectiva, com Gutemberg e a sua máquina de reproduzir grande quantidade de páginas, surge a opinião dos tempos modernos, mais ampla, instigada a debater pelo acesso mais fácil ao conhecimento. Depois, com a mídia de massa (jornais, rádios e TV), tiveram origem as democracias nacionais e a "esfera pública do tamanho de uma nação", conforme sugere o autor. Hoje, chegamos à internet, que possui uma arquitetura informativa completamente diferente e que estaria, segundo o autor, criando um novo tipo de democracia e de opinião pública. "Com a internet, passamos da democracia opinativa para a democracia colaborativa [...]" (DI FELICE, 2010).

Por mais que alguns autores alertem para questões críticas, concernentes ao uso da internet, poucos são os cidadãos, na atualidade, que abririam mão 
de tê-la em suas vidas, o que demonstra o incontestável papel que assume nas atividades culturais, econômicas, políticas e sociais. Não podemos deixar de observar a internet como oportunidade para dar voz aos atores sociais. Especialmente em um momento no qual observarmos a perda generalizada de confiança nas instituições e nos governantes.

\section{CONSIDERACÕES FINAIS}

As redes digitais trazem maior pluralidade de perspectivas para quem persegue a verdade, como propõe Avitizer (2014), pensando na complexidade da circulação das informações e nas oportunidades trazidas pela esfera pública digital. Para o autor (2014, p 66), "não existe uma esfera pública democrática com um único emissor de mensagens, ou um emissor dominante de mensagem". Sem direito à voz pública, o direito de falar e ser ouvido, não há cidadão livre, não se estabelece o princípio da soberania popular sem a opinião pública democrática. Assim, neste novo contexto, como sustenta Lemos (2014, p.8), "a internet e a tecnologia são elementos que catapultaram a ideia de rede para o centro da esfera pública".

Desse modo, por muito que ainda tenhamos de avançar, passamos a observar uma arquitetura informativa que não se limita mais à distribuição de informações, mas age, também, interativa e colaborativamente. As formas de ativismo e de exercício de cidadania que caracterizam os movimentos sociais processados hoje resultam da interação entre os cidadãos, os grupos, as entidades e as tecnologias de informação. A questão das reconfigurações do espaço e do tempo fez com que alguns obstáculos fossem removidos para a participação política. Agora, podemos ter referências de acontecimentos políticos de outros espaços e de outros países, que podem gerar aprendizados para as práticas locais.Nesse sentido, somos otimistas no que concerne às oportunidades abertas, pelas redes digitais, à prática deliberativa. Percebemos que, hoje, essas teias, da forma como se estruturam, permitem maior participação dos atores sociais. De fato, a internet abre espaço para a inclusão de grupos diferenciados na esfera pública; as redes digitais possibilitam a inclusão de discursos heterogêneos, de modo que os interesses coletivos podem ser expressos, mesclando-se. A opinião pública torna-se, assim, mais plural, mediante a inclusão de diversos atores sociais no cenário de debate.

Referências

ARENDT, Hannah. The human condition. Chicago: The University of Chicago Press. 2 edition, 1959. AVRITZER, Leonardo; COSTA, Sérgio. Teoria crítica, democracia e esfera pública: concepções e usos na 
América Latina. Dados: Revista de Ciências Sociais, Rio de Janeiro, v. 47, nº 4, 2004, p.703-728.

AVRITZER, Leonardo. Democracia Participativa, esfera pública e opinião pública democrática. In: Lima, Venício A. de; Guimarães, Juarez; Amorim, Ana Paola (orgs.). Em defesa de uma opinião pública: conceitos, entraves e desafios. São Paulo: Paulus, 2014. p.59-85.

CASTELLS, Manuel. A era da informação. São Paulo: Paz \& Terra, 1999.

_. A Galáxia da Internet: reflexões sobre a internet, os negócios e a sociedade. Rio de Janeiro: Zahar, 2003.

_. A sociedade em rede. São Paulo: Paz e Terra, 2005.

_. Communication power. Oxford: Oxford University Press, 2009.

_. Redes de indignação e esperança: movimentos sociais na era da internet.1.ed. Rio de Janeiro: Zahar, 2013.

—. O poder da comunicação. Paz \& Terra (Grupo Editorial Record), 2015.

DI FELICE, Massimo. Cidadãos 365 dias por ano. Entrevistador: Christian Carvalho Cruz. O Estado de S. Paulo. 24 abr 2010.

- _Netativismo: novos aspectos da opinião pública em contextos digitais. Revista Famecos (Impresso), v. 19, p. 27-45, 2012.

Ser redes: o formismo digital dos movimentos net-ativistas. Revista Matrizes. Revista do Programa de Pós-Graduação em Ciências da Comunicação da Universidade de São Paulo. São Paulo. Ano 7, n ${ }^{\circ} 2$, p. 49-71, (jul/dez) 2013.

—. Manifestações neozapatistas: Estudo examina as formas de interação entre os net-ativistas, as redes digitais e a territorialidade. Entrevistador: Juliana Sayuri. Revista Pesquisa Fapesp. Ed. 217. Março 2014a. Disponível em:

<http://revistapesquisa.fapesp.br/2014/03/10/manifestacoes-neozapatistas/>. Acesso em: 20 mar 2016.

__; LEMOS, Ronaldo. A vida em rede. Campinas, SP: Papirus, 2014. p.8.

FUCHS, Christian. Internet and Society. Social Theory in the Information Age. New York. Routledge, 2008.

_. Mídias sociais e a esfera pública. In: Revista Contracampo, v. 34, n. 3, Niterói: Contracampo, 2015. Págs: 5-80. ed. dez/2015-mar/2016.

GOMES, Wilson. Internet e participação política em sociedade democrática. Revista Famecos, Porto Alegre, PUC-RS, n.27, p.58-78, 2005.

—. A democracia digital e o problema da participação civil na decisão política. 2008a.

__ MAIA, Rousiley, C. M. Comunicação e democracia: problemas \& perspectivas. São Paulo: Paulus, 2008 b.

HABERMAS, Jürgen. The structural transformariam of the public sphere: an inquiry a category of bougeois society. Cambridge: Polity, [1989] 1991.

_. Direito e democracia: entre facticidade e validade, vol.1, Rio de Janeiro: Tempo Brasileiro, 1997.

_. Mudança estrutural da esfera pública: investigações sobre uma categoria da sociedade burguesa. Tradução Denilson Luís Werle. São Paulo. Editora Unesp, 2014.

LEMOS, André. "Ciberativismo". In: Correio Brasiliense, 15 nov 2003. Caderno Pensar. 
_; LÉVY, Pierre. O futuro da internet: em direção a uma ciberdemocracia planetária. São Paulo: Paulus, 2010a.

LÉVY, Pierre. A inteligência coletiva: por uma antropologia do ciberespaço. 4. ed. São Paulo: Loyola, 2003.

LIPPMANN, Walter. Opinião pública. 2.ed, Petrópolis, RJ: Vozes, 2010.

MAIA, Rousiley C. M. Esfera pública e os media na trajetória do pensamento de Jürgen Habermas. In: MARQUES, Ângela et. Al. Esfera pública, redes e jornalismo. Rio de Janeiro: E-papers, 2009, pp 48-69.

PIERRE, B. Sobre o Estado: Cursos no Collège de France. 1 ed. São Paulo: Companhia das Letras, [1989-92] 2014.

RÜDIGER, Francisco Ricardo de Macedo. As Teorias da Cibercultura: perspectivas, questões e autores. Porto Alegre: Sulina, 2011.

THOMPSON, HOHN B. Fronteiras cambiantes da vida pública e privada. Revista Matrizes, Revista do Programa de Pós-Graduação em Ciências da Comunicação da Universidade de São Paulo. ano 4, n 1, (jul./dez. 2010). São Paulo: ECA USP, Paulus: 2010.

A mídia e a modernidade: uma teoria social da mídia. Tradução Wagner de Oliveira Brandão. 15ª ed. Petrópolis, RJ: Vozes, 2014. 